\title{
A TEORIA VISTA DO QUADRO-NEGRO: TENSÕES DA EPISTEMOLOGIA NO DISCURSO DOCENTE SOBRE TEORIA(S) DA COMUNICAÇÃO
}

\author{
THE VIEW FROM THE CHALCKBOARD: TEACHER'S \\ UNDERSTANDING OF EPISTEMOLOGICAL PROBLEMS OF \\ COMMUNICATION THEORY COURSES \\ A MIRADA DESDE LA PIZARRA: LOS PROBLEMAS \\ EPISTEMOLOGICOS DE LA TEORIA DE LA COMUNICACIÓN SEGUN LOS \\ MAESTROS \\ Luís Mauro Sá Martino \\ Professor do PPGCom da \\ Faculdade Cásper Líbero \\ Imsamartino@gmail.com
}

\section{Resumo}

Qual a visão de docentes de Teoria da Comunicação a respeito da constituição e limites epistemológicos de sua disciplina? Essa questão emerge da tensão entre a pluralidade de teorias circulando na área e as demandas disciplinares institucionais. A partir de questionários respondidos por 15 professores de universidades públicas e privadas, escolhidos após pesquisa exploratória prévia, foram delineados três aspectos na resposta dessas questões: (1) as ambivalências epistemológicas da área manifestam-se na discordância a respeito do aspecto coberto pela disciplina; (2) o significado histórico e relevância contemporânea são igualmente levados em conta na escolha dos tópicos; (3) a influência de demandas institucionais e posição nas matrizes curriculares.

Palavras-chave: Teoria da Comunicação; Epistemologia; Ensino; Pesquisa.

\begin{abstract}
How does Communication Theory teachers understand their own discipline? This question arises from the tension between the plurality of theories and the need to establish constitute a syllabus. A survey with 15 Communication Theory teachers from public and private Brazilian universities suggests three main aspects of the answers to this question: (1) There is little agreement on what is studied in "Communication Theory"; (2) teachers take into the account both contemporary relevance and historical significance of the theories; (3) contextual and institutional elements are also relevant for a teacher to include or exclude some topics.
\end{abstract}


Key words: Communication Theory; Epistemology; Teaching; Research

\section{Resumen}

¿Cuál es la opinión de docentes de "Teoría de la Comunicación” sobre su disciplina, su constitución y sus límites? ¿Cómo son escogidos los contenidos? Cuestionários respondidos por 15 profesores de diversas universidades públicas y privadas de Brasil sugeren tres aspectos principales que responden a las siguientes preguntas: (1) las ambivalencias epistemológicas de área se manifiestan en el desacuerdo, entre los maestros sobre el contenido de la disciplina; (2) el significado histórica y relevancia contemporánea se tienen en cuenta en la elección de los temas de la materia, (3) observase la influencia de las demandas institucionales y la posición de curricular.

Palabras clave: Teoría de la Comunicación, Epistemología, Enseñanza, Investigación

Esta obra está licenciada sob uma Licença Creative Commons

\section{INTRODUÇÃO}

Sob certos aspectos, as dimensões epistemológicas presentes no ensino de Comunicação costumam ser relegadas a certa marginalidade nas discussões da área. Pesquisas recentes, sejam referentes ao ensino, seja abordando questões epistemológicas, apresentam certa tendência em trabalhar os dois temas como compartimentos estanques dentro dos estudos da área, abordando as duas temáticas como domínios separados.

Embora existam trabalhos nos quais alguas intersecções entre ensino e epistemologia sejam contempladas, como em Barbosa (2002; 2004), Braga (1992; 2006; 2011), RussiDuarte (2010) e Martino (2012), nota-se certa exclusão mútua entre pesquisas sobre epistemologia (Braga, Lopes e Martino, 2010; Ferreira, Signates e Pimenta, 2010) e a respeito de questões de ensino, como Silva (2006) ou Oliveira-Cruz e Peterman (2010).

O objetivo deste texto é discutir algumas das problemáticas epistemológicas da Comunicação tal como se apresentam materializadas no discurso de professores da disciplina Teoria(s) da Comunicação de 15 universidades brasileiras. Busca-se observar como a epistemologia se materializa nas condições de produção do discurso teórico da área, objetivado nas falas de professores de Teoria da Comunicação.

Foram enviados questionários, via email, a cerca de quarenta docentes dessa disciplina, obtendo-se quinze respostas. Perguntava-se, nos questionários, como os docentes 
definiam seu espaço no campo teórico, bem como os critérios utilizados para definição dos conteúdos programáticos a ser ensinado como tal.

O título deste texto e alguns aspectos da metodologia foram pensados a partir da leitura de Pierucci (1986). Os resultados sugerem que as ambiguidades epistemológicas da área encontram sua materialidade no discurso dos professores a respeito do que constitui a "teoria" da área quando considerada a disciplina "Teoria da Comunicação".

Não se espera, com esse questionamento, encontrar posições fechadas e acabadas, muito menos pontificar qualquer solução imediata. As respostas dos colegas são observadas como interlocuções de um diálogo do qual se faz parte, sem a pretensão de um olhar "de fora" e, muito menos, "de cima", mas na perspectiva de um participante atento às problemáticas compartilhadas nas práticas cotidianas.

A escolha pelo questionário deriva de dois critérios. Em primeiro lugar, pela atuação dos professores como responsáveis pela seleção do que será incluido nos programas de ensino de Teoria(s) da Comunicação. Em certa medida, cabe ao professor, ao elaborar seu programa, decidir se "Semiótica", "Cibercultura" ou "Estudos Culturais", por exemplo, seriam considerados como uma das "teorias da comunicação" ou não - e essa decisão, em que pesem as variáveis institucionais, decorre de referências epistemológicas.

É no conjunto dessas instâncias que o pensamento sobre Comunicação efetivamente se constitui como uma espécie de cânone do que será, para estudantes, "Teoria da Comunicação".

O texto se desenvolve ao redor de eixos constituídos a partir das entrevistas: (1) enquadra-se o corpus de pesquisa no quadro teórico de alguns problemas epistemológicos da área; (2) examina-se a definição oferecida de "Teoria da Comunicação" e de seus elementos constitutivos; (3) observam-se os critérios de escolha de conceitos, autores e métodos na constituição dos programas de ensino. Discutem-se os resultados do levantamento, procurando indicar similitudes, ambivalências e contradições.

\section{DESENVOLVIMENTO}

\subsection{A problemática epistemológica no ensino de Teoria(s) da Comunicação}

Ensinar a Comunicação não se apresenta como um gesto dissociado de pensar a Comunicação. A divisão, frequente nas habilitações dos cursos de Comunicação, entre as disciplinas "técnicas" e "teóricas" está ligada à concepção que se faz da própria 
Comunicação, não apenas em termos epistmeológicos para seu estudo mas também nos aspectos práticos de sua operacionalização professional - cf. Lima (1983). Essa divisão não está isenta de tensões e problemas. Resgatando um texto de Braga (1992, p. 153), é possível identificar, em alguns casos, uma "esquizofrenia” entre uma visão "teórico-sociológico crítica" e as "necessidades de mercado".

Nesse contexto, a especificidade da disciplina Teoria da Comunicação emerge do contraste com outras disciplinas teóricas. Nos cursos de graduação em Comunicação, nesse grupo de matérias, nota-se a presença, muitas vezes predominância, de disciplinas que condensam outras áreas do saber, como Sociologia, Filosofia, Psicologia e Antropologia. Em alguns casos, a aderência à área é explicitada por um tratamento do ambivalente objeto comunicacional a partir do olhar dessas disciplinas, entendidas como "Sociologia da Comunicação", "Psicologia da Comunicação" e assim por diante. Sem diminuir aqui a importância desses olhares, pode-se, por comparação, notar que a disciplina "Teoria da Comunicação" é uma das únicas que parece se referir, em todos os seus aspectos, a uma elaboração teórica específica da Comunicação que, embora no constante diálogo com outras áreas do saber, busca um olhar "de dentro" embora, discutível quanto a seus aspectos epistemológicos, como lembra Martin Algarra (2009).

O ensino de Comunicação, embora seja objeto de discussões e eventos acadêmicos, parece ser pensado sobretudo em âmbito pedagógico - corretamente, um espaço preferencial de vinculação. A proposta, neste caso, é pensar o ensino no espaço das problemáticas epistemológicas da área, entendendo que o discurso teórico nos cursos de Comunicação se articula com os processos de conhecimento da própria área (Cf. Baptista, 2003; Temer, 2007; Barbosa, 2002; 2004).

Nesse sentido, algumas das discussões epistemológicas da área parecem encontrar sua materialidade nos discursos do espaço acadêmico, nos quais os processos de institucionalização e disciplinarização dos saberes demandam a tomada de decisões a respeito do que efetivamente pode ou vai constituir o cânone de uma área (Ferreira, 2003; Martino, L. C. 2007).

O processo disciplinarização institucional dos saberes, recorda Foucault (2003) é em boa medida caudatário dos termos das micropolíticas de distribuição do conhecimento que, em diálogo com as definições e ambivalências dos problemas investigados nas instâncias de produção e discussão epistemológica, constituem os discursos teóricos da área que serão amplamente divulgados nos espaços acadêmicos. 
Em outras palavras, os problemas epistemológicos da área encontram sua materialidade, entre outras instâncias, no discurso da disciplina "Teoria(s) da Comunicação" (cf. Barbosa, 2010). O que busca investigar aqui não é um problema exclusivamente relacionado ao ensino, mas antes uma perspectiva epistemológica relacionada com a definição do que pode ou não ser julgado como pertencente à Comunicação, e quais seriam os critérios para a definição desses vínculos (Otero e Bello, 2006).

A pluralidade epistemológica se comprime em espaços bastante estreitos no momento em que se passa do espaço acadêmico de discussão para o espaço universitário de ensino e pesquisa em graduação e pós-graduação, quando as demandas institucionais exigem definições, recortes e delimitação de conteúdos - veja-se, a respeito, as reflexões de Lozano e Vicente (2010), Sanchez e Campos (2009), Martino (2012). A observação das falas dos professores a respeito dessas problemáticas permite observar algums dessas dimensões.

\section{A especificidade de uma disciplina entre campos teóricos}

As ambivalências presentes na formação de um discurso teórico sobre Comunicação não deixam de encontrar ecos e ressonâncias na fala dos professores a respeito de uma definição a respeito do que é a disciplina ensinada. Se, como a área vem detectando há cerca de uma década, não há consenso a respeito do que constituem o objeto, o método e os conceitos centrais da Comunicação (Lopes, 2006; Romancini, 2006), o discurso docente tampouco parece direcionar esse posicionamento. No discurso dos entrevistados foram identificadas duas respostas principais, uma voltado para a síntese, outra para a problematização.

As primeiras, em geral, pautam-se na concepção de que a área se caracteriza por ser um agregado de vários saberes, sendo Teoria da Comunicação uma disciplina que se articula com essa pluralidade:

(...) O que chamamos de Teoria da Comunicação apresenta-se como um corpo heterogêneo de proposições e enunciados sobre a comunicação, fruto de investigações de diversas filiações (sociologia, antropologia, psicologia, etc.) - cada uma refletindo o olhar e o instrumental metodológico de sua disciplina de origem e promovendo inúmeras interfaces com a comunicação por meio da análise empírica de objetos recortados por um olhar especificamente comunicacional [Docente 01].

A heterogeneidade da área, e, por conseguinte, da disciplina, é igualmente ressaltada no que diz respeito à formação da disciplina, sugerindo a pertinência da ideia de que se trata quase, no risco do paradoxo, de uma "disciplina interdisciplinar" (cf. Martino, 2011), como está na resposta de outro colega: 
São fundamentos teóricos, particularmente originários das ciências sociais, e depois dos campos da linguagem, para pesquisas e estudos sobre a produção, difusão e recepção de bens simbólicos mediados por suportes técnicos tipográficos, eletrônicos e digitais [Docente 09].

Em sentido semelhante, três entrevistados destacam a abordagem histórica dos fenômenos comunicacionais como instâncias de definição da disciplina. O critério histórico, pensado também na definição dos conteúdos (v. próximo ítem) é ressaltado como um dos elementos constitutivos da disciplina:

A disciplina Teorias da Comunicação é o conjunto das perspectivas teóricas, oriundas de várias áreas do conhecimento, que historicamente vêm sendo usadas para compreender, explicar e interpretar os fenômenos do campo comunicacional, particularmente da comunicação midiática e, mais recentemente, pela comunicação mediada pelas novas tecnologias [Docente03].

Nas palavras de outro colega:

Resume-se as várias abordagens e interfaces feitas a respeito do Processo de Comunicação por autores com formação diversa, tendo o contexto histórico como influência direta à criação das teorias que, de certa forma, retratam a realidade das sociedades da época [Docente05].

De certa maneira, essas falas parecem refletir um posicionamento relativamente comum na definição de Teorias da Comunicação como um conjunto de teorias ou escolas teóricas desenvolvidas de maneira mais ou menos linear ao longo do século $\mathrm{XX}$, às quais se somariam discussões a respeito da Internet e das mídias digitais no século XXI. É possível encontrar ressonâncias de práticas institucionalizadas, tanto nos programas de ensino quanto na bibliografia da área (Martino, L.M., 2008; 2011; Martino, L. C., 2007) em uma seqüência de teorias e saberes que, como observa um colega citado, são "particularmente originários das ciências sociais, e depois dos campos da linguagem" [Docente 9].

No caso, a especificação dos livros intitulados "Teoria da Comunicação" como substrato da definição da disciplina sugere uma interferência desse processo de institucionalização do saber refletido nas publicações com esse título:

Um conjunto de teorias científicas relacionadas à área de Comunicação Social eleito por autores que se tornaram referência clássica para essa disciplina por terem lançado livros com o título fazendo referência às Teorias da Comunicação, obras que expõem mais ou menos suscintamente cada uma das escolas teóricas [Docente07].

Pode-se destacar, na apreensão de uma certa modalidade institucional do discurso de “Teoria da Comunicação", o recurso aos livros da área como uma das instâncias de definição do que é a disciplina, nos quais se destaca igualmente o aspecto cronológico e interdisciplinar da reflexão teórica incorporada à área.

Outro grupo de respostas delineia-se no sentido de apontarem para a dispersão epistemológica da área, indicando não só a existência de um campo ainda em construção mas 
também a dificuldade de estabelecer o que pode ou não ser fazer parte do campo de significados cobertos pela teoria. A própria possibilidade de resposta é questionada por um dos entrevistados:

Pergunta ingrata: há muita confusão entre Teorias da Comunicação e teorias que abordam a comunicação, bem como confusão entre "comunicação" e "comunicação de massa". Na minha visão, Teorias (no plural) da Comunicação dizem respeito ao conjunto de teorias que abordam os fenômenos comunicativos (perdão pela aparente redundância), não sendo estes necessariamente apenas os fenômenos midiáticos [Docente10].

A reflexão sobre as diferentes propostas dentro de uma "Teoria da Comunicação", que se desdobraria na especificidade do que é "comunicação" em contraste com a "comunicação de massa" ou mesmo com uma "teoria da mídia" é um ponto de reflexão trazido à tona pelos docentes. No mesmo sentido, as ambivalências decorrentes da relação teoria-prática são pensadas como elementos constitutivos do universo das teorias da comunicação. A ausência de especificidade epistemológica da disciplina - que não se confunde com a especificidade frente às outras matérias "teóricas" discutida acima - é notada também nesse contexto. Nas palavras de outro docente:

Primeiramente, sou alinhado com a visão de que não há uma teoria da comunicação, o singular, mas se tratam de teorias da comunicação, ou seja, a área se constitui de um conjunto diverso de pensamentos sistematizados, de "concretos em pensamento", numa perspectiva de interação entre práticas cotidianas/profissionais e reflexões sistematizadas/programas reflexivos, que buscam dar conta de problemáticas em torno dos processos de produção, circulação, consumo, armazenamento e reprodução de distintas formas simbólicas, no contexto da interação humana e social [Docente 04].

A problematização epistemológica, nessa mesma linha, é objeto de reflexão por parte de alguns docentes na elaboração do que pode ou deve entender por "Teoria da Comunicação". Se as questões específicas da disciplina são elaboradas ainda no nível de suas dinâmicas internas nas respostas anteirores, um dos entrevistados a situou em um foco maior, enquadrando a discussão nos problemas de constituição da área:

(...) entendo Teorias da Comunicação como uma disciplina que busca compreender todos estes processos que foram dando corpo ao campo da Comunicação, desde os primeiros estudos feitos por estudiosos de outras áreas até as pesquisas mais recentes em que passamos a ter mais autonomia e garantir um maior espaço [Docente 11].

No nível macro da constituição da disciplina, observam-se ressonâncias das ambivalências epistemológicas da área. Não há consenso a respeito da formação da disciplina, seu objeto ou abordagens específicas na medida em que tanto as respostas voltadas para a síntese quanto aquelas que problematizam a questão sugerem a indefinição das fronteiras da disciplina, pensada na maior parte das vezes como uma trama de conceitos advindos de outros espaços de saber - cf. Lasorsa (2002). 
Diante do vasto campo de significados atribuídos a essa disciplina, pode-se questionar de que maneira é factível objetivar esses saberes na constituição de uma única matéria dentro de matrizes curriculares universitárias; a diversidade epistemológica apontada pelos docentes, em algum momento, articula-se com as demandas institucionais de definição de ementas, tópicos, conteúdos programáticos e bibliografias. Nesse momento a diversidade epistemológica precisa ser ordenada em esquemas de caráter organizador, eventualmente burocrático, que darão forma a uma conjunto de saberes - jogando com os termos, é o momento em que a variedade epistemológica é "disciplinada".

Esse processo certamente tem uma dimensão de seleção, escolha e exclusão de autores e conteúdos, o que requer algum critérios. Dado que, como sugerido, esse critério não parece advir de definições epistemológicas por conta de sua ausência, passa-se, no próximo ítem, ao questionamento de quais elementos regem essas escolhas.

\section{Critérios e escolhas na disciplinarização da epistemologia}

Se, como visto, as preocupações epistemológicas parecem sofrer significativas alterações no momento em que são convertidas em um programa de ensino, talvez seja lícito perguntar o que consta desses programas quais são os critérios responsáveis pela sua elaboração. Dado que há uma gama multifatorial de possibilidades no que tange a essa escolha, foi perguntado aos colegas quais eram os parâmetros utilizados para a escolha do que entra ou fica de fora de um programa de ensino.

As consequências dessa pergunta se desdobram em ao menos duas direções.

Em primeiro lugar, por se tratar de programas de ensino no âmbito dos cursos de Graduação, é esperado que seja um contato inicial entre os alunos e o núcleo teórico da área escolhida, de maneira que, como observado em outros momentos, há uma possibilidade considerável que o conteúdo apresentado pelo docente seja entendido como o todo de teorias da Comunicação disponíveis para serem estudadas.

Além disso, é preciso observar uma confluência de fatores na escolha dos assuntos que pertencerão aos programas de ensino. Em primeiro lugar, vale lembrar que essa disciplina ocupa um espaço determinado dentro de uma matriz curricular, e a escolha de conteúdos em algum medida passa pela intersecção com outras disciplinas - é necessário pensar, por exemplo, em que medida caberia um tópico sobre Semiótica dentro de "Teorias da Comunicação" em instituições nas quais haverá um ou mais semestres da disciplina "Semiótica". Um dos respondentes sistematizou esse desdobramento em sua resposta: 
O programa da disciplina é elaborado num processo de negociação entre a ementa constituída no PPC do Curso de Comunicação Social da [Nome da Universidade Suprimido] e questões que vejo como necessárias no contexto atual. Há também o problema de que a disciplina tem somente 4 créditos e aplicada somente uma vez no curso. Depois, o aluno tem Semiótica e Pesquisa em Comunicação como outras disciplinas [Docente 04].

Vale ter em mente, portanto, que os programas de ensino não existem como discursos autônomos e separados do espaço institucional no qual são produzidos e colocados em prática. As relações entre disciplinas dentro dos cursos universitários também é pensado como critério, sobretudo por conta da indefinição de fronteiras da material, recordam Craig (1999) e Martino, L. M. (2011; 2012). No âmbito da "Teoria da Comunicação", isso significa a divisão de todo uma variada gama de estudos dentro de ementas, tópicos e bibliografias.

Note-se, como afirmado, que a inclusão/exclusão de assuntos pauta-se também na perspectiva mais abrangente do curso: no texto acima, por exemplo, as semióticas compõe o âmbito da disciplina - cf. Sholle (1995). Em outra instituição, a existência de um divisão tripartite implica outra forma de alocação dos conteúdos que podem ser tratados sob essa rubrica:

Temos 3 disciplinas de Teoria da Comunicação, a que ministro é Teoria II, e este é o programa: Visão crítica e epistemológica, centrada nos princípios de mediação e vinculação que visa problematizar questões como: espaço público e imagem pública, verdade e doxa, representação e simulação, mediação e mediatização, realizando a análise da passagem da sociedade moderna disciplinar para o modelo contemporâneo de redes e controle.

Os critérios foram a definição do campo de estudos e o encadeamento das 3 disciplinas de Teoria da Comunicação [Docente 06].

Em última análise, apenas a título de comentário, seria necessário observar até mesmo em que medida relações pessoais e institucionais dentro dos departamentos e cursos de Comunicação poderiam contribuir para a elaboração dos programas - algo fora do escopo dentre artigo - ver, por exemplo, Streeter (1995) ou, para uma análise detalhada, Bourdieu $(1983 ; 1987)$.

Neste momento, no entanto, cumpre reparar que essas origens nem sempre são explicitadas pelos docentes. Ao contrário, quase todos os entrevistados - exceto o citado acima - optaram por evidenciar as razões das definições dos programas sem mencionar os espaços institucionais de sua vinculação.

Um dos critérios é histórico, tomando a sucessão de teorias como um ponto de partida para a constituição dos programas. Em certa medida, por conta das mencionadas ambivalências epistemológicas da área, trata-se de se pautar em um discurso teórico já consagrado - embora, evidentemente, não deixe de ser objeto de discussão.

O discurso sobre teoria da comunicação no âmbito do ensino universitário, dessa 
maneira, articula-se com as ambivalências presentes na área da qual essa teoria marca, ou deveria marcar, o referencial de estudos. No entanto, nota-se uma preocupação constante em estabelecer, ao lado dos eixos históricos principais, temáticas contemporâneas. Se há um predomínio do que poderiam ser as teorias "clássicas", como as pesquisas norte-americanas, a Escola de Frankfurt, McLuhan e a Teoria das Mediações (cada uma delas aparecendo de maneiras diversas na escrita dos professores), há igualmente uma perspectiva de agregar discussões contemporâneas, em especial sobre Cibercultura.

$\mathrm{O}$ critério diacrônico, portanto, não se afirma como o único. E, mesmo quando isso acontece, é indicado no texto de alguns respondentes a perspectiva de aproximação sincrônica desses referenciais.

Finalmente, pensando nos sujeitos vistos a partir da frente da sala, vale observar que dois dos entrevistados colocaram os alunos, em perspectiva que ecoa Bruck (1985) e Hickson e Staks (1993), como um dos critérios de definição dos conteúdos a serem compartilhados. Um deles deixa isso explícito:

$\mathrm{Na}$ verdade vou mudando o foco da disciplina de acordo com o grupo de alunos que recebo. Um ano privilegio as correntes teóricas, em outro os autores, em outro ainda as escolas de pensamento. Meu planejamento tem tudo a ver com a turma que recebo [Docente 07].

Dessa maneira, a perspectiva de construção da disciplina parece obedecer, em primeiro lugar, a um princípio de consagração prévia dos conteúdos das teorias ditas "clássicas", somados às demandas atuais de trabalho dentro da área. Vale notar que o espaço da prática profissional foi mencionado apenas um dos docentes.

\section{CONSIDERAÇÕES}

O problema epistemológico das teorias da Comunicação tem inúmeras dimensões, podendo ser pensado desde sua existência, como faz Martino, L. C. (2001; 2005) até a necessidade de seu ensino, na perspectiva de Russi-Duarte (2010) ou, em recuo temporal, de Lins da Silva (1978).

Espaço por excelência de elaboração das discussões epistemológicas da área, com as quais se articula e reflete parcialmente, a disciplina parece ser delineada a partir de uma série de problemas de definição comuns à Área - o que pode, até certo ponto, ser esperado, na medida em que as ambivalências epistemológicas de uma área do conhecimento parecem se reproduzir em menor escala em outras dimensões, como o ensino e a pesquisa. Como recorda Muniz Sodré (2008, p.19), as classificações das áreas do saber vão além de um exercício de 
taxonomia com vistas a definir onde serão alocados alguns tipos de conhecimento, mas de observar a constituição de uma episteme.

A partir dos questionários com os docentes, foi possível notar em que medida essas ambivalências teórico-metodológicas se articulam - talvez fosse mais exato dizer "se refletem" - no momento em que a disciplina será especificamente construída como parte de um curso de graduação em Comunicação. Na elaboração dos programas de ensino, os problemas epistemológicos partem de uma indefinição a respeito do próprio escopo e limites da disciplina, ora pensada como um conjunto de teorias consagradas, principal aspecto presente nas entrevistas, ora entendida como o estudo de meios ou processos comunicacionais. Entende-se que é nesse momento que as discussões epistemológicas elaboradas por pesquisadores e discutidas nos eventos da área encontra algumas condições de ser pensada em sua materialidade enquanto discurso objetivado nos programas de ensino. As entrevistas, aqui, procuraram de alguma maneira problematizar essa objetivação, ressaltando não o que seria um contraponto de seu aspecto subjetivo, embora isso não deixe de ser indiretamente contemplado, mas procurando observar, na explicitação feita pelos docentes em suas respostas, quais são esses critérios e definições.

Na medida em que a área de Comunicação enfrenta de modo recorrente discussões a respeito de seus limites e termos constitutivos, talvez não seja de todo uma surpresa que a disciplina na qual se congregam os núcleos teóricos da área apresentem os mesmos problemas de limites, foco e aportes.

Mais do que isso, foi possível notar uma certa preocupação dos docentes em estabelecer limites para a disciplina ancorados na consagração institucional prévia, bem como a adequação contemporânea.

A pluralidade dos discursos das professoras e professores sugere uma ambiguidade epistemológica que não é estranha à área, manifestando-se no âmbito de suas definições do que é "Teoria da Comunicação", quais os seus limites e escopo. Mediador de um saber a ser compartilhado e reelaborado, os docentes mostram na escrita uma articulação com a área e seus problemas, sobretudo na diversidade e trânsito de significados a uma única pergunta, talvez a que não possa ser respondida de pronto e, de alguma forma, orientou esta pesquisa o que é Teoria da Comunicação. 


\section{REFERÊNCIAS}

BAPTISTA, M. L. C. Disciplinas Teóricas: de entulho de currículo a campo do desejo e autopoiesis. Trabalho apresentado no XXVI Congresso Anual da Intercom. Belo Horizonte/MG, 02 a 06 de setembro de 2003.

BARBOSA, M. A pesquisa em Comunicação no século XXI: bases para uma nova ciência?. IN: MELO, J. M. e GOBBI, M. C. Pensamento comunicacional latino-americano. São Paulo: Unesco/Metodista, 2004.

BARBOSA, M. Paradigmas de construção do campo comunicacional. In. HOHFELDT, A. et alli. Tensões e Objetos da Pesquisa em Comunicação. Porto Alegre, Sulina, 2002.

BONIN, J. A. Elementos para pensar a formação e o ensino em teorias da comunicação.

Revista Conexão - Comunicação e Cultura, UCS, Caxias do Sul, v. 4, n. 8, p. 61-68, jul./dez. 2005

BRAGA, J. L. A formação de professores para a Comunicação. In: KUNSCH, M. M. K. O ensino de Comunicação. São Paulo: Abecom, 1992.

BRAGA, J. L. Ensino e pesquisa em Comunicação. Texto apresentado em mesa-redonda no Intercom Sul - Curitiba, maio de 2006.

BRAGA, J. L. A prática da pesquisa em Comunicação: abordagem metodológica como tomada de decisões. E-compós, v.14, n.1, jan./abr. 2011

BRAGA, J. L., LOPES, M. I. V. e MARTINO, L. C. Pesquisa Empírica em Comunicação. São Paulo: Paulus, 2011.

BRUCK, P. A. Theoretical practice and intellectual work: teaching critical communication theory. Canadian Journal of Communication. no. 11, vol. 1, 1985, pp. 75-86.

CRAIG, R. “Communication Theory as a Field” Communication Theory 9(2) May 1999.

EPSTEIN, I. Um impasse curricular: Teoria da Comunicação. IN: MELO, J. M. Ensino de Comunicação no Brasil: impasses e desafios. São Paulo: Eca/Usp, 1987.

FRANÇA, V. Paradigmas da Comunicação: conhecer o quê?. In: MOTTA, Luiz Gonzaga; FRANÇA, V., PAIVA, R. e WEBER, M. H. (orgs.) Estratégias e culturas da comunicação. Brasília: Editora UnB, 2001.

HICKSON, M. e STACKS, D. W. Teaching the Introductory Communication Theory Course to Undergraduates. Communication Quarterly, Vol. 41, No. 3, Summer 1993, Pages 261268

LASORSA, D. L. Diversity in Mass Communication Theory Courses. Journalism and Mass Communication Educator. Autumn 2002.

LINS DA SILVA, C. E. Teoria da Comunicação. In: FADUL, A. \& MELO, J. M. Ideologia e Poder no Ensino de Comunicação. São Paulo: Cortez, 1978.

LOPES, M. I. V. O campo da Comunicação: sua constituição, desafios e dilemas. Revista 
Famecos. No. 30: Agosto 2006, pp. 16 - 30.

LOPES, M. I. V. Sobre o estatuto disciplinar do campo da Comunicação. In: Epistemologia da Comunicação. São Paulo: Loyola, 2003.

LOZANO A., C. y VICENTE M., M. (2010): La enseñanza universitaria de las Teorías de la Comunicación en Europa y América Latina. Revista Latina de Comunicación Social, 65. La Laguna (Tenerife): Universidad de La Laguna, pp/ 255 a 265

MARTIN ALGARRA, M. La comunicación como objeto de estudio de la teoría de la comunicación. Anàlisi, 38, 2009, pp. 151-172.

MARTINO, L. C. Apontamentos epistemológicos sobre a fundação e a fundamentação do campo comunicacional. In: CAPPARELLI, S. et alli. A Comunicação Revisitada. Porto Alegre: Sulina, 2005.

MARTINO, L. C. Elementos para uma epistemologia da Comunicação. In: VVAA. Campo da Comunicação. João Pessoa: Editora da UFPB, 2001.

MARTINO, L. M. S. A disciplina interdisciplinar. Texto apresentado no GT Estudos Interdisciplinares no XVI Intercom Sudeste. São Paulo, 10 a 12 de maio de 2011.

MARTINO, L. M. S. A ilusão teórica no campo da comunicação. Famecos, no.38. Junho-. Agosto. Porto Alegre, 2008.

MATTOS, M. A. Desafios para a aformação e o reconhecimento da identidade teóricoepistemológica do campo comunicacional e seus agentes acadêmicos. In: FERRREIRA, G. M. e MARTINO, L. C. Teorias da Comunicação. Salvador, Edufba, 2007.

OLIVEIRA-CRUZ, M. C. B. F. e PETERMAN, J. Entre a prática e a teoria. Animus - revista interamericana de comunicação midiática.

OTERO BELlO, E. El estado del arte en teoria de la comunicación. Ciencias Sociales Online, Marzo 2006, Vol. III, No. 1. Universidad de Viña del Mar-Chile (70-90)

ROMANCINI, R. O campo científico da Comunicação no Brasil. São Paulo: ECA-USP, 2006 (Tese de Doutorado).

ROMANCINI, R. O campo científico da Comunicação no Brasil. São Paulo, Tese (Doutorado) - Escola de Comunicações e Artes - USP, 2006.

RUSSI-DUARTE, P. Por que ensinar teorias (da comunicação)?. Trabalho apresentado no GT Teorias da Comunicação durante o XXXIII Congresso Brasileiro de Ciências da Comunicação - UCS - 6 a 9 de setembro de 2010.

SANTAELLA, L. Comunicação e Pesquisa. São Paulo: Hacker, 2003.

SANTOS, T. C. Teorias da Comunicação: caminhos, buscas e intersecções. Revista Famecos. Porto Alegre, no. 28, dezembro 2005, p. 163.

SHOLLE, D. Resisting Disciplines: Repositioning Media Studies in the University. Communication Theory, 5 (2), 1995, pp.130-143.

SILVA, M. Currículo e Ensino de Comunicação. UNIrevista, Vol. 1, no. 03, Julho 2006.

SODRÉ, M. Ensinar e Pesquisar. In: MOREIRA, S. V. e VIEIRA, J. P. D. Comunicação: 
ensino e pesquisa. Rio de Janeiro: Ed. UERJ, 2008.

STREETER, T. Introduction: For The Study of Communication and Against the Discipline of Communication. Communication Theory, 5(2), 1995, pp. 117-129.

TEMER, A. C. Teorizar é pensar a prática: uma reflexão sobre o ensino das Teorias da Comunicação nos Cursos de Jornalismo. Texto apresentado no $10^{\circ}$ Encontro Nacional de Professores de Jornalismo - Goiânia-GO - 27 a 30 de abril de 2007.

WOOD, Andrew F. e FASSET, Deanna L. Remote Control: Identity, Power, and Technology in the Communication Classroom', Communication Education,52:3,286 - 296, 2003.

Original recebido em: 17/03/2015

Aceito para publicação em: 05/08/2015

Luis Mauro Sa Martino

Jornalista e Professor na graduação e pós-graduação em Comunicação na Contemporaneidade da Faculdade Cásper Líbero. Doutor em Ciências Sociais pela PUC-SP. Foi pesquisador-bolsista na Universidade de East Anglia, Inglaterra. Autor dos livros "Teoria da Comunicação" (Vozes, 2009) e

"Comunicação \& Identidade" (Paulus, 2010), entre outros. 